\title{
Liposomal bupivacaine: a review of a new bupivacaine formulation
}

This article was published in the following Dove Press journal:

Journal of Pain Research

13 August 2012

Number of times this article has been viewed

\section{Praveen Chahar \\ Kenneth C Cummings III}

Anesthesiology Institute, Cleveland Clinic Foundation, Cleveland, Ohio, USA
Correspondence: Kenneth Cummings III Cleveland Clinic Foundation, 9500 Euclid Avenue, Mail code G30, Cleveland,

$\mathrm{OH} 44195$, USA

$\mathrm{Tel}+\mathrm{I} 2164441016$

$\mathrm{Fax}+\mathrm{I} 2164444383$

Email cummink2@ccf.org

\begin{abstract}
Many attempts have been made to increase the duration of local anesthetic action. One avenue of investigation has focused on encapsulating local anesthetics within carrier molecules to increase their residence time at the site of action. This article aims to review the literature surrounding the recently approved formulation of bupivacaine, which consists of bupivacaine loaded in multivesicular liposomes. This preparation increases the duration of local anesthetic action by slow release from the liposome and delays the peak plasma concentration when compared to plain bupivacaine administration. Liposomal bupivacaine has been approved by the US Food and Drug Administration for local infiltration for pain relief after bunionectomy and hemorrhoidectomy. Studies have shown it to be an effective tool for postoperative pain relief with opioid sparing effects and it has also been found to have an acceptable adverse effect profile. Its kinetics are favorable even in patients with moderate hepatic impairment, and it has been found not to delay wound healing after orthopedic surgery. More studies are needed to establish its safety and efficacy for use via intrathecal, epidural, or perineural routes. In conclusion, liposomal bupivacaine is effective for treating postoperative pain when used via local infiltration when compared to placebo with a prolonged duration of action, predictable kinetics, and an acceptable side effect profile. However, more adequately powered trials are needed to establish its superiority over plain bupivacaine.
\end{abstract}

Keywords: liposomal bupivacaine, postoperative pain, pharmacokinetics, pharmacodynamics, efficacy, safety

\section{Introduction}

Pain is a protective mechanism which has adaptive value, and the inability to experience pain has been linked to early mortality from accidental injuries or damage to joints. ${ }^{1,2}$ However, pain in the postoperative setting is an unwanted side effect of surgery directed to improve morbidity or mortality. The potential benefits of optimal postoperative pain control include: improved cardiac, respiratory, and gastrointestinal functions; fewer thromboembolic complications; improved arterial graft survival; fewer septic complications; reduced chronic post surgical pain; reduced mortality in high-risk patients; and reduced health care costs. ${ }^{3}$ Opioids have been the cornerstone of relief for perioperative pain; however, opioids have numerous side effects including nausea, vomiting, respiratory depression, prolonged ileus, itching, tolerance, and development of opiate induced hyperalgesia. ${ }^{4,5}$

Increasingly, multimodal analgesia is used to reduce perioperative opiate requirements, thus potentially reducing opioid side effects and improving the quality of analgesia. ${ }^{6,7}$ Local anesthetics are increasingly used perioperatively via different routes 
as part of a multimodal regimen. ${ }^{8}$ The use of bolus injection of local anesthetics is limited by duration of post operative pain relief with the average duration of block via interscalene injection being 8 to 12 hours with either bupivacaine $0.5 \%$ or ropivacaine $0.5 \%$ or $0.75 \% .{ }^{9}$ Local anesthetic infusions via catheters are used to increase the duration of postoperative analgesia $;{ }^{10}$ however, placement and maintenance of perineural catheters involves additional training ${ }^{11}$ in addition to the added cost of pumps. ${ }^{12}$

Complications due to perineural catheters are infrequent but can be life threatening, and these complications can include infection, septicemia, intravascular placement, or intravascular catheter migration. ${ }^{13}$ The development of new, long acting local anesthetics, like liposomal bupivacaine is potentially important in the management of perioperative pain. This article will review liposomal bupivacaine as a potential addition to the clinician's analgesic armamentarium.

\section{Liposomal bupivacaine}

Liposomes are microscopic structures consisting of a phospholipid bilayer encapsulating an aqueous core. They may be unilamellar, multilamellar, or multivesicular. Unilamellar liposomes consist of a single lipid bilayer surrounding the aqueous core, whereas multilamellar liposomes consist of concentric lipid layers. Multivesicular liposomes (MVL), however, consist of nonconcentric lipid bilayers. The nonconcentric nature of MVL confers characteristic drug release patterns from the aqueous core that are different from the unilamellar and multilamellar liposomes, leading to increased stability and longer duration of drug release. The release of drug from the MVL requires only a breach in the external layer, and release of a drug from internal vesicles leads to redistribution of the drug within the particle without release. The multivesicular structure also ensures that the vesicles rearrange themselves without release of drug by internal fusion and division. ${ }^{14,15}$ These vesicles can encapsulate water soluble drugs in their core, and lipid soluble drugs within the membrane. They are used in the systemic delivery of antifungals, antineoplastics, and antibiotics. ${ }^{16,17}$ Currently available liposomal bupivacaine consists of vesicles of bupivacaine loaded in the aqueous chambers using DepoFoam ${ }^{\circledR}$ technology (Pacira Pharmaceuticals Inc, San Diego, CA). Each particle is composed of a honeycomb like structure of numerous internal aqueous chambers containing encapsulated bupivacaine ${ }^{18,19}$ (Figures 1 and 2).

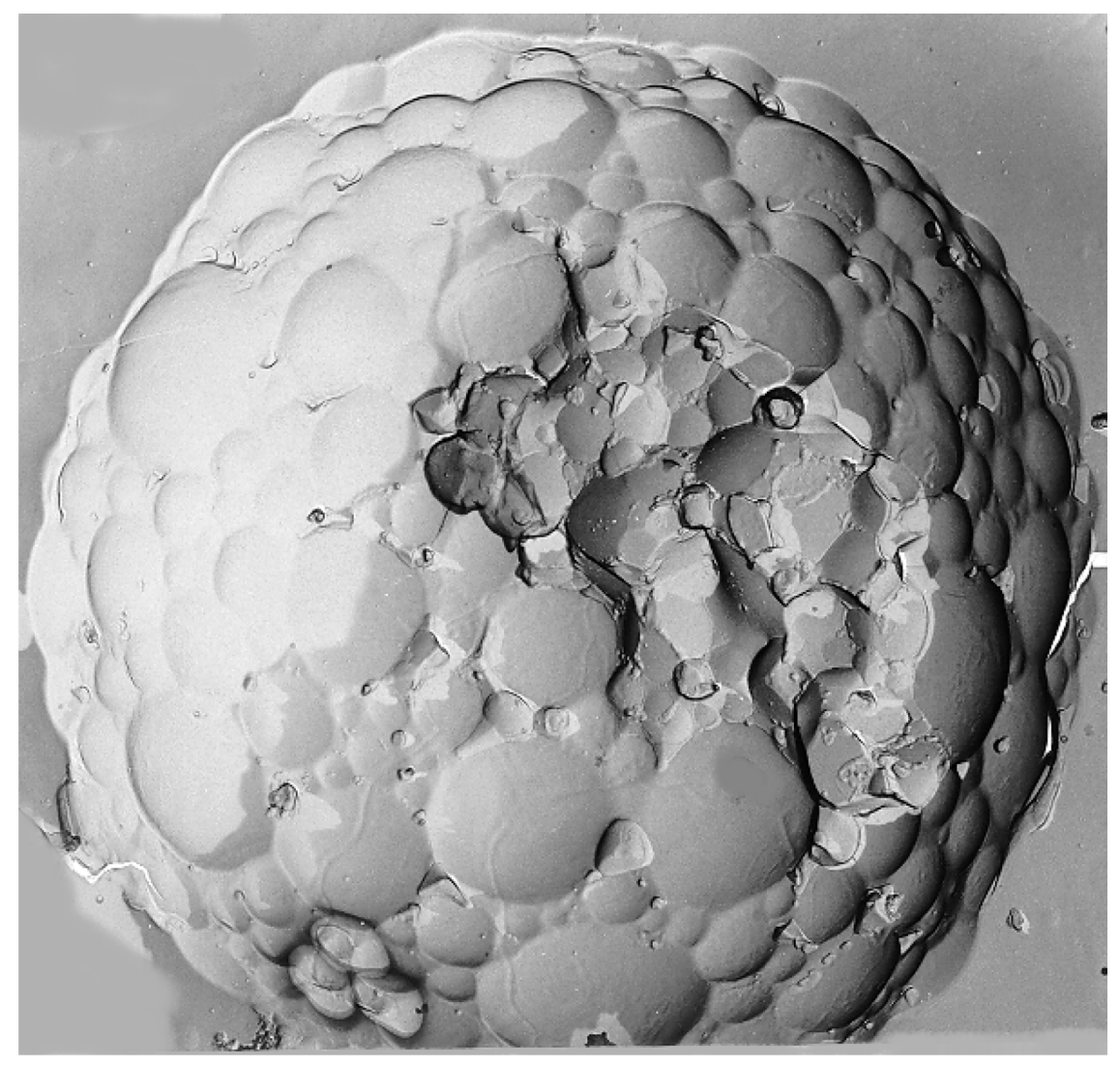

Figure I Scanning electron microscope image of DepoFoam ${ }^{\circledast}$ containing bupivacaine. Image supplied courtesy of Pacira Pharmaceuticals, Inc, 5 Sylvan Way, Parsippany, NJ 07054. 


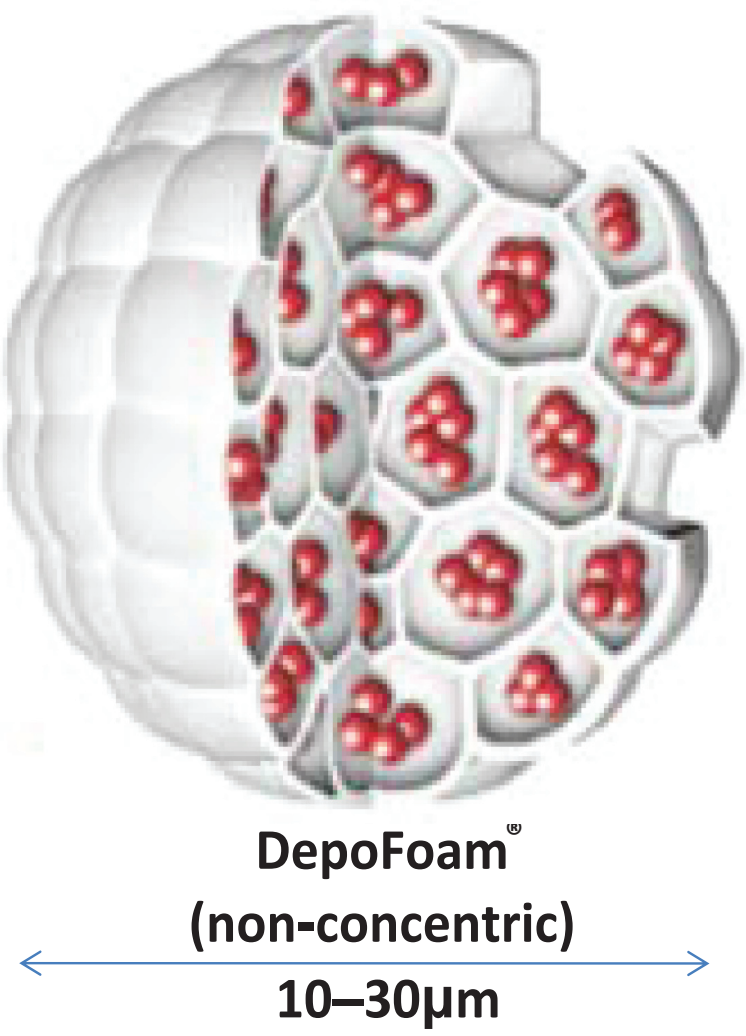

Figure 2 Cross-sectional diagram of DepoFoam containing bupivacaine. Image supplied courtesy of Pacira Pharmaceuticals, Inc, 5 Sylvan Way, Parsippany, NJ 07054.

\section{Pharmacodynamics}

Bupivacaine is an amide local anesthetic, which acts by inactivating voltage-dependent sodium channels. It has a $\mathrm{pKa}$ of 8.1 so only $15 \%$ is present in uncharged form at tissue $\mathrm{pH}$. The uncharged fraction of bupivacaine travels across the cell membrane of the nerve, and once charged binds to the inner side of sodium channels, inactivating them. ${ }^{20}$ The release of bupivacaine from its binding site is slow, which leads to a longer duration of action than lidocaine. ${ }^{21}$

\section{Pharmacokinetics}

The pharmacokinetics of MVL bupivacaine have been studied in both animal and human models. Richard et $\mathrm{al}^{18}$ compared MVL bupivacaine in doses of 9,18 , and $30 \mathrm{mg} / \mathrm{kg}$ with $9 \mathrm{mg} / \mathrm{kg}$ of plain bupivacaine injected by wound infiltration in rabbits. They found the $\mathrm{C}_{\max }$ to be dose dependent, being $107 \pm 27.6,222 \pm 28.3$, and $307 \pm 148 \mathrm{ng} / \mathrm{mL}$ for the three doses of MVL bupivacaine, respectively. However, the $\mathrm{C}_{\max }$ was much lower than plain bupivacaine $(620 \pm 89.9 \mathrm{ng} / \mathrm{mL})$. The plasma bupivacaine concentration in the group receiving plain bupivacaine peaked quickly compared to the MVL bupivacaine group: $1 \pm 0 \mathrm{~h}$ compared to $12.5 \pm 8.06,7.0 \pm 11.3$, and $30.3 \pm 22.5$ hours for the three doses of MVL bupivacaine, respectively. Plasma bupivacaine concentrations were detectable in most animals (dogs) who received MVL bupivacaine $9 \mathrm{mg} / \mathrm{kg}$ over a 96-hour study period.

In the pharmacokinetic study of human volunteers, Davidson et $\mathrm{al}^{22}$ compared subcutaneous injection of $20 \mathrm{~mL}$ of $2 \%$ liposomal bupivacaine versus $20 \mathrm{~mL}$ of $0.5 \%$ plain bupivacaine. They found no difference in the $\mathrm{C}_{\max }$ between the two groups $(0.87 \pm 0.45$ versus $0.83 \pm 0.34$ in plain and liposomal groups, respectively) despite a 4-fold increase in bupivacaine dose and a 9.8-fold increase in the terminal half-life displayed by the liposomal bupivacaine group $(131 \pm 58$ versus $1294 \pm 860 \mathrm{~min}$ in plain and liposomal groups, respectively). The $\mathrm{T}_{\max }$ increased seven-fold in the liposomal bupivacaine group compared to the group administered plain bupivacaine, which was attributable to the slow release of liposomal bupivacaine. The attributes of slow release leading to prolonged $\mathrm{T}_{\max }$ and long $\mathrm{T} 1 / 2$ leading to prolonged detectable plasma concentration of liposomal bupivacaine have been confirmed in a subsequent Phase II, multicenter clinical trial conducted by Langford et al. ${ }^{23}$

Bupivacaine is metabolized mainly in the liver by glucuronide conjugation and hepatic N-dealkylation into pipecolylxylidine. Pipecolylxylidine is then hydroxylated and forms glucuronide conjugates. A small amount of bupivacaine is excreted unchanged in urine. ${ }^{24}$ In a pharmacokinetic study of liposomal bupivacaine in patients with moderate hepatic impairment, Onel et $\mathrm{al}^{25}$ found that although bupivacaine and pipecolylxylidine concentrations were higher in patients with moderate hepatic impairment than in patients with normal hepatic function, the concentration time plots were similar in both groups, and the differences were small enough not to warrant dose adjustments as per Food and Drug Administration (FDA) guidelines.

\section{Efficacy in postoperative pain}

Liposomal bupivacaine has been FDA approved for single dose wound infiltration in postoperative pain relief among patients undergoing hemorrhoidectomy and bunionectomy. ${ }^{26}$ Gorfine et $\mathrm{al}^{27}$ conducted a multicenter, randomized, double blind, placebo-controlled trial in patients undergoing hemorrhoidectomy. At the end of surgery, patients were randomized to receive either $300 \mathrm{mg}(30 \mathrm{~mL})$ extended release MVL bupivacaine or placebo $(30 \mathrm{~mL}$ of $0.9 \%$ sodium chloride) in $5 \mathrm{~mL}$ increments via wound infiltration. Intraoperative use of all analgesics or local anesthetics, except fentanyl, was prohibited unless needed for the treatment of adverse effects. Patients remained at the 
study center for 72 hours, and were administered postsurgical analgesia in response to breakthrough pain consisting of morphine sulfate as needed.

The primary outcome measure consisted of a cumulative pain score in the first 72 hours as reflected in the $\mathrm{AUC}_{0-72}$ (area under the curve) numerical rating score (NRS) of pain intensity. Secondary efficacy measures consisted of assessing the proportion of patients who received no opioid rescue medications, total amount of opioid rescue medications consumed, time to first postsurgical use of rescue medications, and the patient's rating of satisfaction with postsurgical analgesia. The researchers found the pain scores to be markedly lower in the bupivacaine extended release group compared to those receiving the placebo with a least mean square (SE) AUC ranging from 0 to 72 hours of 141.8 (10.7) in the MVL bupivacaine group versus 202.5 (10.7) in the placebo group $(P<0.0001)$. In the bupivacaine extended release group, $59 \%$ of patients were opioid free at 12 hours, and $28 \%$ were opioid free at 72 hours when compared to $14 \%$ and $10 \%$ in the placebo group, respectively ( $P<0.0008$ through 72 hours). In addition, the mean total amount of opioid consumed was lower in the MVL bupivacaine group (22.3 mg vs $29.1 \mathrm{mg}$, $P \leq 0.0006)$, and the median time to first opioid use was longer (14.3 hours vs 1.2 hours with $P<0.0001)$ and was associated with greater patient satisfaction with postoperative analgesia $(95 \%$ vs $73 \%, P=0.0007)$ when compared to placebo.

Golf et $\mathrm{al}^{28}$ conducted a multicenter, parallel group, placebo controlled, randomized, double blind study in which they compared extended release MVL bupivacaine to placebo in patients undergoing bunionectomy. The patients underwent primary first metatarsal bunionectomy under midazolam and/ or propofol sedation with Mayo block with up to $25 \mathrm{~mL}$ of $2 \%$ lidocaine with epinephrine. Within 30 minutes after injection of lidocaine, the patients received either a single dose of $120 \mathrm{mg}(8 \mathrm{~mL})$ extended release bupivacaine or placebo ( $8 \mathrm{~mL} 0.9 \%$ sodium chloride) by local infiltration. Patients were observed for 24 hours at the study center. Rescue analgesia consisted of $5 \mathrm{mg}$ oxycodone $/ 325 \mathrm{mg}$ acetaminophen tablets up to a maximum of 12 tablets per day with a single dose of intravenous ketorolac $15-30 \mathrm{mg}$ as a second rescue. The primary outcome measure was the AUC of NRS pain scores through 24 hours. Secondary outcome measures consisted of: the proportion of patients who received no rescue pain medications; AUC of NRS pain scores through $36,48,60$, and 72 hours; the proportion of patients who were pain free during the observation period; the time to first rescue medication use; and total oxycodone/acetaminophen consumption through $24,36,48,60$, and 72 hours. The researchers found markedly reduced pain intensity scores at 24 and 36 hours post injection in the MVL bupivacaine group compared to placebo $(P=0.0005$ and $P=0.0229$ at 24 and 36 hours) with no difference at 48 hours $(P=0.1316)$. The percentage of patients who were pain free showed a statistically significant difference at $2,4,8$, and 48 hours only in the MVL bupivacaine group $(P<0.05)$, with more patients in the MVL bupivacaine group not receiving any rescue pain medication through 24 hours only $(P<0.05)$. The time to first opioid use was longer ( 7.2 hours vs 4.3 hours, $P<0.0001$ ), and fewer mean total number of oxycodone/ acetaminophen tablets were used through 24 hours (3.8 vs 4.7 tablets, $P=0.0077$ ) in the MVL bupivacaine group compared to the placebo group.

Smoot et $\mathrm{al}^{29}$ conducted a randomized, multicenter, double blind, parallel group, active control study comparing MVL bupivacaine $300 \mathrm{mg}$ to bupivacaine $\mathrm{HCl} 100 \mathrm{mg}$ (bupivacaine $0.5 \%$ with epinephrine $1: 200,000$ ) in patients undergoing bilateral cosmetic submuscular breast augmentation. At the end of the surgical procedure, the patients received either $300 \mathrm{mg}$ of MVL bupivacaine or $100 \mathrm{mg}$ of bupivacaine $\mathrm{HCl}$ (with epinephrine) on each side, injected locally at the breast implant pockets at the end of surgery. Postoperatively, the patients received $1000 \mathrm{mg}$ of acetaminophen three times daily with rescue analgesia (oxycodone) for breakthrough pain through 96 hours. The primary outcome measure was the AUC of NRS pain scores through 72 hours. Secondary outcomes consisted of cumulative pain scores at time points other than 72 hours, proportion of patients not requiring rescue analgesia, total amount of rescue opioid medication consumed, and integrated rank assessment through multiple time points.

The mean cumulative pain score (numeric rating score with activity through 72 hours) was not significantly different in the two groups (441.5 in the MVL bupivacaine group vs 468.2 in the bupivacaine $\mathrm{HCl}$ group, $P=0.3999$ ). The lack of a difference was attributed to a lack of statistical power. The NRS pain score with activity mean (SE) was markedly lower in the MVL bupivacaine group at 8 and 12 hours [4.9 (0.41) and $5.6(0.40)]$ compared with the bupivacaine $\mathrm{HCl}$ group [6.7 (0.40) and $6.9(0.37), P=0.0016$ and 0.0143 , respectively]. The difference in mean (SE) pain scores at rest was also lower in the MVL bupivacaine group at 8 hours only compared to the bupivacaine $\mathrm{HCl}$ group [3.5 $(0.35)$ vs $5.0(0.34)$ respectively $(P=0.027)]$. The total amount of postsurgical rescue opioid medication used at 24 and 48 hours was also lower in the MVL bupivacaine 
group compared to the bupivacaine $\mathrm{HCl}$ group $(P=0.0211$ and 0.0459 , respectively).

Bramlett et $\mathrm{al}^{30}$ performed a randomized, double blind study comparing wound infiltration of MVL bupivacaine to bupivacaine $\mathrm{HCl}$ for postsurgical analgesia in total knee arthroplasty. They compared $150 \mathrm{mg}$ of bupivacaine $\mathrm{HCl}$ (with 1:200,000 epinephrine) to MVL bupivacaine in doses of $133 \mathrm{mg}, 266 \mathrm{mg}, 399 \mathrm{mg}$, and $532 \mathrm{mg}$. The patients were between 18-75 years old and were classified as American Society of Anesthesiologists physical status 1-3 patients undergoing unilateral knee replacement under general anesthesia. For 24 hours prior to surgery, all patients received $1000 \mathrm{mg}$ of acetaminophen three times daily. Intraoperatively, only intravenous fentanyl use was permitted. The study medications were diluted in $60 \mathrm{~mL}$ of $0.9 \%$ saline and were injected via local infiltration in the deep tissues, the capsulotomy incision, and the subcutaneous tissues intraoperatively. Postoperatively, patients received a single dose of a nonsteroidal anti-inflammatory drug parentally with oral acetaminophen. For rescue analgesia, patientcontrolled intravenous morphine was used until patients could be switched to oral oxycodone 5-10 mg every 4-6 hours once oral intake was established. The primary outcome measure was AUC of NRS pain scores with activity (NRS-A) through day 4. Secondary outcome measures consisted of: AUC of NRS-A through time points other than day 4; AUC of NRS pain scores at rest (NRS-R); NRS-R and NRS-A scores at each assessed time point; total consumption of opioid rescue medications; total consumption of opioid medications; time to resumption of daily activities; and provider's satisfaction with postoperative analgesia on day 8 .

There was no difference between the groups for the primary outcome measure of the mean AUC of NRS pain scores with activity. The mean (SD) scores were 20.4 (3.9) in the bupivacaine $\mathrm{HCl}$ group versus 19.1 (4.4), 18.8 (5.3), 19.5 (5.3), and 20.7 (5.4), in the MVL bupivacaine $532 \mathrm{mg}$, $399 \mathrm{mg}, 266 \mathrm{mg}$, and $133 \mathrm{mg}$ groups, respectively. There was no detectable difference in the groups with regard to mean numeric rating scale pain scores, total consumption of rescue opioids, or the time to resumption of work or normal daily activities (Table 1).

Boogaerts et $\mathrm{al}^{31}$ compared $0.5 \%$ bupivacaine (with 1:200,000 epinephrine) with $0.5 \%$ liposomal bupivacaine (a multilamellar formulation different from the clinically available multivesicular DepoFoam) administered epidurally for the management of postsurgical pain. The patients were classified as American Society of Anesthesiologists physical status 2 and 3 undergoing major abdominal surgery.

Table I Studies comparing the efficacy of MVL bupivacaine versus placebo or bupivacaine $\mathrm{HCl}$

\begin{tabular}{|c|c|c|c|c|c|}
\hline Author & $\begin{array}{l}\text { Type } \\
\text { of study }\end{array}$ & Comparison & Surgery & Primary outcome & Results \\
\hline $\begin{array}{l}\text { Gorfine } \\
\text { et } \mathrm{al}^{27}\end{array}$ & $\mathrm{RCT}$ & $\begin{array}{l}300 \text { mg DepoFoam } \\
\text { bupivacaine compared } \\
\text { with placebo }\end{array}$ & Hemorrhoidectomy & $\begin{array}{l}\text { AUC }_{0-72} \text { of NRS } \\
\text { pain intensity scores }\end{array}$ & $\begin{array}{l}\text { Least square mean (SE) } \mathrm{AUC}_{0-72} 141.8(\mathrm{I} 0.7) \\
\text { in the DepoFoam bupivacaine }(\mathrm{n}=94) \text { group } \\
\text { compared to } 202.5(10.7) \text { in placebo } \\
(\mathrm{n}=93) . P<0.000 \mathrm{I} \text {. }\end{array}$ \\
\hline $\begin{array}{l}\text { Golf } \\
\text { et } \mathrm{al}^{28}\end{array}$ & $\mathrm{RCT}$ & $\begin{array}{l}\text { I } 20 \text { mg DepoFoam } \\
\text { bupivacaine compared } \\
\text { with placebo }\end{array}$ & Bunionectomy & $\begin{array}{l}\text { AUC }_{0-24} \text { of NRS } \\
\text { pain intensity scores }\end{array}$ & $\begin{array}{l}\text { Least square mean (SE) } \mathrm{AUC}_{0-24} \text { I } 23.936 \\
(4.4854) \text { in DepoFoam bupivacaine group } \\
(\mathrm{n}=93) \text { compared to } 146.233(4.5869) \text { in } \\
\text { placebo }(\mathrm{n}=92) . P<0.0005 .95 \% \mathrm{Cl} \\
\text { of difference between DepoFoam } \\
\text { bupivacaine vs placebo }-34.799 \text { to }-9.794 \text {. }\end{array}$ \\
\hline $\begin{array}{l}\text { Smoot } \\
\text { et } \mathrm{al}^{29}\end{array}$ & $\mathrm{RCT}$ & $\begin{array}{l}600 \mathrm{mg} \text { DepoFoam } \\
\text { bupivacaine compared } \\
\text { with } 200 \mathrm{mg} \text { bupivacaine } \\
\mathrm{HCl} \text { with epinephrine } \\
\mathrm{I}: 200,000\end{array}$ & $\begin{array}{l}\text { Submuscular } \\
\text { augmentation } \\
\text { mammoplasty }\end{array}$ & $\begin{array}{l}\text { AUC }_{0-72} \text { of NRS-A } \\
\text { pain intensity scores }\end{array}$ & $\begin{array}{l}\text { Mean (SE) } \text { AUC }_{0-72} 44 \mathrm{I} .5(23.6) \text { in } \\
\text { DepoFoam bupivacaine group }(n=66) \\
\text { and } 468.2(23.0) \text { in bupivacaine } \mathrm{HCl} \text { group } \\
(\mathrm{n}=70) . P=0.3999 .\end{array}$ \\
\hline $\begin{array}{l}\text { Bramlett } \\
\text { et } \mathrm{al}^{30}\end{array}$ & $\mathrm{RCT}$ & $\begin{array}{l}\text { Bupivacaine } \mathrm{HCl} I 50 \mathrm{mg} \\
(0.5 \%) \text { with epinephrine } \\
\text { I:200,000 compared with } \\
\text { four doses of DepoFoam } \\
\text { bupivacaine }(133,266, \\
399 \text {, and } 532 \mathrm{mg})\end{array}$ & $\begin{array}{l}\text { Total knee } \\
\text { arthroplasty }\end{array}$ & $\begin{array}{l}\text { AUC }_{0-96} \text { of NRS-A } \\
\text { pain intensity scores }\end{array}$ & $\begin{array}{l}\text { Mean (SD) } 20.7(5.4), \text { I } 9.5(5.3), \text { I } 8.8(5.3) \text {, } \\
\text { and I } 9.1 \text { (4.4) in DepoFoam bupivacaine } \\
\text { I } 33 \mathrm{mg}, 266 \mathrm{mg}, 399 \mathrm{mg} \text {, and } 532 \mathrm{mg} \text { groups } \\
\text { ( } \mathrm{n}=25,24,26 \text {, and } 2 \text { I, respectively) and } \\
20.4(3.9) \text { in the bupivacaine } \mathrm{HCl} \text { group } \\
(\mathrm{n}=30) . P \text { value }>0.05 \text { in each DepoFoam } \\
\text { bupivacaine group compared to } \\
\text { bupivacaine } \mathrm{HCl} \text { group. }\end{array}$ \\
\hline
\end{tabular}

Abbreviations: AUC, area under the curve; MVL, multivesicular liposomes; NRS, numerical rating score; NOS, not otherwise specified; NRS-A, numerical rating score with activity; RCT, randomized clinical trial; SD, standard deviation; SE, standared error. 
The epidural catheter was inserted with a test dose of bupivacaine $(0.5 \% 3 \mathrm{~mL})$ with epinephrine $1: 200,000$ given at the time of insertion. Postoperatively, when patients experienced pain after complete recovery of motor function, they received a $10 \mathrm{~mL}$ bolus of either liposomal bupivacaine $0.5 \%$ or $10 \mathrm{~mL}$ of plain bupivacaine $0.5 \%$ (with 1:200,000 epinephrine). The researchers found no detectable difference in the time of onset of analgesia (13.75 $\pm 1.25 \mathrm{~min}$ in the plain bupivacaine group versus $13.92 \pm 1.58 \mathrm{~min}$ in the liposomal bupivacaine group), though the duration of analgesia increased significantly in the liposomal bupivacaine group $(6.25 \pm 1.13$ hours in the liposomal bupivacaine group versus $3.2 \pm 0.4$ hours in the plain bupivacaine group, $P<0.05$ ). In a subset of patients who underwent abdominal aortic surgery, the duration of analgesia was $10.6 \pm 1.4$ hours in the liposomal bupivacaine group versus $2.42 \pm 0.35$ hours in the plain bupivacaine group $(P<0.001)$. There was no motor block in the liposomal bupivacaine group though intraoperative surgical anesthesia was not observed with the liposomal bupivacaine group. The lack of surgical block was thought to be due to alterations in the pharmacodynamics of the drug preventing the necessary amount of free bupivacaine available at the site of action, thus producing only postsurgical analgesia. There are no studies evaluating the epidural use of DepoFoam bupivacaine to assess whether the lack of surgical analgesia is seen with the DepoFoam formulation as well.

\section{Safety}

Bupivacaine may produce many adverse effects. The most common life threatening side effects involve the cardiovascular and central nervous systems. ${ }^{32,33}$ Bupivacaine is more cardiotoxic than lidocaine, and it produces its toxicity by producing cardiac conduction block. ${ }^{34}$ Animal studies have shown that bupivacaine uncouples oxidative phosphorylation, may induce apoptosis in muscle cells, and may cause Schwann cell damage. The damage to Schwann cells happens in both a time as well as a concentration dependent fashion. ${ }^{35}$ The myotoxicity of bupivacaine is well described and may be related to $\mathrm{Ca}^{2+}$-induced apoptosis of muscle cells. The myotoxicity of bupivacaine is most pronounced after retrobulbar and peribulbar blocks with an overall incidence of anesthesia-related diplopia reported to be $0.25 \% .^{36,37}$ Although the diplopia may resolve spontaneously, it may require surgical correction. ${ }^{38}$

The most common side effects of MVL bupivacaine in clinical trials included nausea, vomiting, constipation, pyrexia, dizziness, and headache. ${ }^{28,30}$ Bergese et $\mathrm{al}^{39}$ compared the cardiac safety of MVL bupivacaine in four doses $(150,300,450$, or $600 \mathrm{mg})$ to bupivacaine $\mathrm{HCl}$ with epinephrine injected via wound infiltration intraoperatively in patients undergoing total knee arthroplasty. They found no significant differences in change from baseline in QRS or QTc duration in the two groups, nor did the two groups differ in mean change from baseline heart rate and PR interval. Naseem et $\mathrm{al}^{40}$ examined the effect of four doses of MVL bupivacaine $(300,450,600$, and $750 \mathrm{mg}$ ) injected subcutaneously on the QTc interval in healthy volunteers. None of the participants receiving MVL bupivacaine had a maximum QTc interval greater than $500 \mathrm{~ms}$, and there were no changes in QTc of greater than $60 \mathrm{~ms}$ at any measured time point.

In a 2-year follow up study assessing the effect of MVL bupivacaine on the integrity of breast implants after augmentation mammoplasty, Minowitz et $\mathrm{al}^{41}$ found no negative impact of intraoperative use of MVL bupivacaine on the integrity of breast implants. Local anesthetics have inhibitory effects on platelet aggregation in response to different agonists. Pinto et $\mathrm{al}^{42}$ studied the effect of multilamellar liposomal local anesthetics on the inhibition of platelet aggregation in response to adenosine diphosphate. They found that encapsulation of local anesthetics into liposomes increased the inhibitory effect of local anesthetics; however, the clinical impact (if any) of this finding remains to be seen in larger trials. In an animal studies by Richard et al ${ }^{18,19}$ evaluating the safety and efficacy of MVL bupivacaine compared to plain bupivacaine and saline, the authors did find granulomatous inflammation in the MVL bupivacaine group, which was considered to be a normal reaction to liposomes; however, there was no effect on wound healing. MVL bupivacaine did not alter wound healing or wound scarring when used for postsurgical analgesia after total knee arthroplasty in humans. ${ }^{30}$

DepoFoam $^{\circledR}$ should not be coadministered with any other local anesthetic as it may increase the release of bupivacaine from the liposomes. It should not be allowed to come in contact with antiseptics like chlorhexidine or povidine iodine as they may disrupt the lipid layers leading to uncontrolled release of bupivacaine. ${ }^{43}$

\section{Discussion}

DepoFoam-encapsulated bupivacaine is a new formulation of bupivacaine that provides slow sustained release of bupivacaine from multivesicular liposomes. Compared to placebo, it has been shown to produce prolonged analgesia with an opioid sparing effect, although more adequately powered trials are needed to assess its efficacy and duration of 
analgesia compared to standard local anesthetic solutions. At present, it is approved by the FDA for use via local infiltration after bunionectomy and hemorrhoidectomy. It has not been shown to be more toxic compared to plain bupivacaine, and it does not have markedly different cardiac effects than plain bupivacaine. It appears safe for use in patients with moderate hepatic impairment and does not warrant dose adjustment in that group. ${ }^{25}$ It has not been evaluated for use via intrathecal, epidural, or perineural administration or in pediatric and pregnant patients. ${ }^{43}$ More multicenter trials are needed to evaluate its efficacy and safety in these populations. If its safety and efficacy are established for epidural, intrathecal, and perineural use, it holds a potentially valuable place in the analgesic arsenal for use against postoperative pain and may substantially reduce the cost and complications associated with catheter and local anesthetic infusion pumps. In addition, the opioid sparing effects of MVL bupivacaine are valuable in potentially reducing opioid-related side effects. This in turn may reduce unwanted hospital admissions related to postoperative pain or opioid side effects.

In summary, the current literature studying MVL bupivacaine has, in general, demonstrated prolonged analgesia and reduced opioid side effects compared to placebo. However, its increased analgesic efficacy (and cost effectiveness) compared to plain bupivacaine in various clinical settings needs to be evaluated in adequately powered clinical trials. At present, the literature supports only a limited role for MVL bupivacaine. This may change as larger studies are conducted.

\section{Acknowledgements}

Figure 1 and a copy of References 23, 25, 39, and 40 were provided by Pacira Pharmaceuticals, Inc, 5 Sylvan Way, Parsippany, NJ 07054. The company had no input in the preparation or editing of this manuscript.

\section{Disclosure}

The authors report no conflicts of interest in this work.

\section{References}

1. Acerbi A, Parisi D. The evolution of pain. In: Costa FA, Rocha LM, Costa E, Harvey I, Coutinho A, editors. Advances in Artificial Life. ECAL 2007: Proceedings of the 9th Annual Conference on Advances in Artificial Life; September 10-14, 2007; Lisbon, Portugal. Berlin: Springer; 2007 : 816-824.

2. Loeser JD, Melzack R. Pain: an overview. Lancet. 1999;353(9164): 1607-1069.

3. Breivik H. Pain management. Baillieres Clin Anaesthesiol. 1994;8(4): 775-795.

4. Koppert W, Schmelz M. The impact of opioid-induced hyperalgesia for postoperative pain. Best Pract Res Clin Anaesthesiol. 2007;21(1):65-83.
5. Chau DL, Walker V, Pai L, Cho LM. Opiates and elderly: use and side effects. Clin Interv Aging. 2008;3(2):273-278.

6. Buvanendran A, Kroin JS. Multimodal analgesia for controlling acute postoperative pain. Curr Opin Anaesthesiol. 2009;22(5):588-593.

7. Dahl V, Raeder JC. Non-opioid postoperative analgesia. Acta Anaesthesiol Scand. 2000;44(10):1191-1203.

8. Tuncer S, Aysolmaz G, Reisli R, Erol A, Yalçin N, Yosunkaya A. The effects of the administration of subfacial levobupivacaine infusion with the ON-Q pain pump system on postoperative analgesia and tramadol consumption in cesarean operations. Agri. 2010;22(2):73-78.

9. Borgeat A, Ekatodramis G. Anaesthesia for shoulder surgery. Best Pract Res Clin Anaesthesiol. 2002;16(2):211-225.

10. Osada R, Zukawa M, Seki E, Kimura T. Continuous peripheral nerve block in forearm for severe hand trauma. Hand Surg. 2011;16(3):239-244.

11. Chelly JE, Delaunay L, Williams B, Borghi B. Outpatient lower extremity infusions. Best Pract Res Clin Anaesthesiol. 2002;16(2): 311-320.

12. Richman JM, Liu SS, Courpas G, et al. Does continuous peripheral nerve block provide superior pain control to opioids? A meta-analysis. Anesth Analg. 2006;102(1):248-257.

13. Chelly JE, Ghisi D, Fanelli A. Continuous peripheral nerve blocks in acute pain management. Br J Anaesth. 2010;105 Suppl 1:i86-i96.

14. Mantripragada S. A lipid based depot (DepoFoam technology) for sustained release drug delivery. Prog Lipid Res. 2002;41(5): 392-406.

15. New RRC. Influence of liposome characteristics on their properties and fate. In: Philippot JR, Schuber F, editors. Liposomes as Tools in Basic Research and Industry. Boca Raton: CRC Press; 1995:3-20.

16. Mowat JJ, Mok MJ, MacLeod BA, Madden TD. Liposomal bupivacaine. Extended duration nerve blockade using large unilamellar vesicles that exhibit a proton gradient. Anesthesiology. 1996;85(3): 635-643.

17. Ostro MJ, Cullis PR. Use of liposomes as injectable-drug delivery systems. Am J Hosp Pharm. 1989;46(8):1576-1587.

18. Richard BM, Ott LR, Haan D, et al. The safety and tolerability evaluation of DepoFoam bupivacaine (bupivacaine extended-release liposome injection) administered by incision wound infiltration in rabbits and dogs. Expert Opin Investig Drugs. 2011;20(10):1327-1341.

19. Richard BM, Newton P, Ott LR, et al. The safety of EXPAREL ${ }^{\circledR}$ (bupivacaine liposome injectable suspension) administered by peripheral nerve block in rabbits and dogs. J Drug Deliv [Serial on the Internet]. Jan 2012 [cited July 2, 2012];962101:[10 p.]. http://www. hindawi.com/journals/jdd/2012/962101/. Accessed July 2, 2012.

20. Dullenkopf A, Borgeat A. Local anesthetics. Differences and similarities in the "-cains". Anaesthesist. 2003;52(4):329-340.

21. Covino BG. Pharmacology of local anaesthetic agents. Br J Anaesth. 1986;58(7):701-716.

22. Davidson EM, Barenholz Y, Cohen R, Haroutiunian S, Kagan L, Ginosar Y. High-dose bupivacaine remotely loaded into multivesicular liposomes demonstrates slow drug release without systemic toxic plasma concentrations after subcutaneous administration in humans. Anesth Analg. 2010;110(4):1018-1023.

23. Langford RM, Chappell GM, Karrasch JA. A single administration of DepoBupivacaine (TM) intraoperatively results in prolonged detectable plasma bupivacaine and analgesia in patients undergoing inguinal hernia repair. Poster presented at: 62nd Annual Postgraduate Assembly of the New York State Society of Anesthesiologists; December 12-16, 2008; New York, NY.

24. Gantenbein M, Attolini L, Bruguerolle B, et al. Oxidative metabolism of bupivacaine into pipecolylxylidine in humans is mainly catalyzed by CYP3A. Drug Metab Dispos. 2000;28(4):383-385.

25. Onel E, Warnott K, Lambert W, Patou G. Pharmacokinetics of depobupivacaine (EXPAREL ${ }^{\mathrm{TM}}$ ), a novel bupivacaine extended release liposomal injection, in volunteers with moderate hepatic impairment. Poster presented at: 112th Annual Meeting of the American Society of Clinical Pharmacology and Therapeutics; March 3-6, 2011; Dallas, TX. 
26. US Food and Drug Administration. FDA Label Approved on 10/28/2011 (PDF) for EXPAREL. US Silver Spring, MD: US Food and Drug Administration. Available from: http://www.accessdata.fda.gov/drugsatfda_ docs/label/2011/022496s0001bl.pdf. Accessed May 01, 2012.

27. Gorfine SR, Onel E, Patou G, Krivokapic ZV. Bupivacaine extended-release liposome injection for prolonged postsurgical analgesia in patients undergoing hemorrhoidectomy: a multicenter, randomized, double-blind, placebo-controlled trial. Dis Colon Rectum. 2011;54(12):1552-1559.

28. Golf M, Daniels SE, Onel E. A phase 3, randomized, placebo-controlled trial of DepoFoam ${ }^{\circledR}$ bupivacaine (extended-release bupivacaine local analgesic) in bunionectomy. Adv Ther. 2011;28(9):776-788.

29. Smoot JD, Bergese SD, Onel E, Williams HT, Hedden W. The efficacy and safety of DepoFoam bupivacaine in patients undergoing bilateral, cosmetic, submuscular augmentation mammoplasty: a randomized, double-blind, active-control study. Aesthet Surg J. 2012;32(1):69-76.

30. Bramlett K, Onel E, Viscusi ER, Jones K. A randomized, doubleblind, dose-ranging study comparing wound infiltration of DepoFoam bupivacaine, an extended-release liposomal bupivacaine, to bupivacaine $\mathrm{HCl}$ for postsurgical analgesia in total knee arthroplasty. Knee. In press: January 27, 2012.

31. Boogaerts JG, Lafont ND, Declercq AG, et al. Epidural administration of liposome-associated bupivacaine for the management of postsurgical pain: a first study. J Clin Anesth. 1994;6(4):315-320.

32. AstraZeneca Canada. Bupivacaine Prescribing Information. Mississauga, ON: AstraZeneca Canada Inc. Available from: http:// www.astrazeneca.ca/documents/ProductPortfolio/SENSORCAINE_ PM_en.pdf. Accessed April 28, 2012.

33. Tucker GT, Mather LE. Clinical pharmacokinetics of local anaesthetics. Clin Pharmacokinet. 1979;4(4):241-278.
34. Wolfe JW, Butterworth JF. Local anesthetic systemic toxicity: update on mechanisms and treatment. Curr Opin Anaesthesiol. 2011;24(5):561-566.

35. Yang S, Abrahams MS, Hurn PD, Grafe MR, Kirsch JR. Local anesthetic Schwann cell toxicity is time and concentration dependent. Reg Anesth Pain Med. 2011;36(5):444-451.

36. Zink W, Graf BM. Local anesthetic myotoxicity. Reg Anesth Pain Med. 2004;29(4):333-340.

37. Gómez-Arnau JI, Yangüela J, González A, et al. Anaesthesia-related diplopia after cataract surgery. Br J Anaesth. 2003;90(2):189-193.

38. Vlăduțiu C, Sevan S, Ciuică M. Diplopia through toxic myopathy after cataract surgery. Oftalmologia. 2008;52(4):77-82.

39. Bergese SD, Onel E, Morren M, Morganroth J. Bupivacaine extendedrelease liposome injection exhibits a favorable cardiac safety profile. Reg Anesth Pain Med. 2012;37(2):145-151.

40. Naseem A, Harada T, Wang D, et al. Bupivacaine extended release liposome injection does not prolong QTc interval in a thorough QT/QTc study in healthy volunteers. J Clin Pharmacol. Epub November 4, 2011.

41. Minkowitz HS, Onel E, Patronella CK, Smoot JD. A two-year observational study assessing the safety of DepoFoam bupivacaine after augmentation mammaplasty. Aesthet Surg J. 2012;32(2):186-193.

42. Pinto LM, Pereira R, de Paula E, de Nucci G, Santana MH, Donato JL. Influence of liposomal local anesthetics on platelet aggregation in vitro. J Liposome Res. 2004;14(1-2):51-59.

43. Pacira Pharmaceuticals, Inc. Exparel (Bupivacaine Liposome Injectable Suspension) Product Monograph. Parsippany, NJ: Pacira Pharmaceuticals, Inc. Available from: http://www.exparel.com/pdf/ Exparel_Monograph.pdf. Accessed May 01, 2012.
Journal of Pain Research

\section{Publish your work in this journal}

The Journal of Pain Research is an international, peer-reviewed, open access, online journal that welcomes laboratory and clinical findings in the fields of pain research and the prevention and management of pain. Original research, reviews, symposium reports, hypothesis formation and commentaries are all considered for publication.

\section{Dovepress}

The manuscript management system is completely online and includes a very quick and fair peer-review system, which is all easy to use. Visit http://www.dovepress.com/testimonials.php to read real quotes from published authors. 